\title{
Turismo e degradação na orla do Rio Grande do Sul: conflitos e gerenciamento
}

\section{Tourism and Degradation in the Coastline of Rio Grande do Sul: Conflicts and Management}

\author{
Luana Carla PORTZ* \\ Rogério Portantiollo MANZOLLI** \\ Nelson Luiz Sambaqui GRUBER ${ }^{* * *}$ \\ Iran Carlos Stalliviere CORREA***
}

\begin{abstract}
RESUMO
O desenvolvimento sustentável da orla marinha põe em conflito os interesses econômicos, ecológicos e socioculturais. Para garantir a sustentabilidade e a vitalidade destas três funções de forma simultânea, tornam-se necessárias ações de planejamento e gestão de modo a reduzir estes conflitos. A importância deste ambiente para a indústria do turismo possui uma necessidade de preservação sociocultural e conservação ecológica como única forma de manter o desenvolvimento econômico. O município de Xangri-lá, que apresenta sua economia voltada para a área de serviços ao turismo e ao veraneio, está iniciando suas atividades de manejo das dunas e uso e ocupação da faixa de praia. Este trabalho tem como objetivo detalhar a situação atual da orla marinha do município de Xangri-lá e os conflitos existentes em decorrência do turismo na região. Para tanto, foram realizadas investigações dos problemas e conflitos existentes na orla marinha através de observações de campo, de perfis topográficos e de vegetação. Durante este período, constatou-se o agravamento da erosão sobre o sistema de dunas, ocasionada pelas tempestades e pela diminuição da vegetação, resultando na sua diminuição em tamanho e largura. Associadas a isso, a pressão da ocupação e a falta de infraestrutura de suporte ao turismo e ao veraneio foram dos principais problemas encontrados na orla. Outro agravante é a descaracterização do sistema de dunas, causado pelo pisoteio da vegetação nativa, invasão de vegetação exótica, construções de condomínios, jardins e quiosques. Além disso, o descaso dos usuários frente à importância deste ambiente tem levado ao acúmulo de resíduos sólidos. As medidas imediatas para o não comprometimento das atividades econômicas frente à erosão e à degradação da orla estão na recuperação das dunas frontais, melhorias de acesso à praia por meio da manutenção adequada dos sangradouros e passarelas e locais
\end{abstract}

\footnotetext{
" Mestre em Geociências. Universidade Federal do Rio Grande do Sul, Instituto de Geociências, Centro de Estudos de Geologia Costeira e Oceânica. Doutoramento em Ciências do Programa de Pós-Graduação em Geociências, área de concentração em Geologia Marinha. Email: luanaportz@gmail.com

"* Oceanólogo. Universidade Federal do Rio Grande do Sul, Instituto de Geociências, Centro de Estudos de Geologia Costeira e Oceânica. Mestrando do Programa de Pós-Graduação em Geociências, área de concentração em Geologia Marinha. Email: rogeriomanzolli@gmail.com

*** Doutor em Geociências. Universidade Federal do Rio Grande do Sul, Instituto de Geociências, Centro de Estudos de Geologia Costeira e Oceânica. Email: nelson.gruber@ufrgs.br

***** Doutor em Oceanologia. Universidade Federal do Rio Grande do Sul, Instituto de Geociências, Departamento de Geodésia. Email: iran.correa@ufrgs.br
} 
adequados para dispor os resíduos sólidos, além da comunicação como fonte geradora de informação e conhecimento sobre esta problemática e suas consequências para a sociedade.

Palavras-chaves: turismo; Xangri-lá; gerenciamento costeiro.

\begin{abstract}
Economic, ecological and socio-cultural interests always come into conflict within the Sustainable Coastal Development. In order to ensure the sustainability and vitality of these three functions simultaneously, planning and management actions are necessary to reduce these conflicts. Coastal environment is of great importance for the tourism industry, so it is necessary to assure socio-cultural and ecological conservation as the only way to maintain economic development. The municipality of Xangri-lá, which has its economy focused on tourism, is starting dunes management activities and reorganizing the use and occupation of the beach. This paper aims to detail the current situation of the coast of Xangri-lá and the conflicts as a result of tourism in this area. The problems and conflicts were evaluated through field observations and morphodynamic controls (profile of the beach and vegetation). During this period it was found that there is an aggravation of erosion on the dune system, caused by storms and a vegetation decrease. As a result, dunes decreased in size and width. Associated to this, the pressure of occupation and the lack of infrastructure related to tourism were the main problems found along the coast. Another problem is the dune system distortion caused by the trampling of native vegetation, exotic vegetation invasion, buildings, condominiums, gardens and kiosks. Furthermore, the users' neglect about the importance of this environment has been leading to the accumulation of garbage. The immediate measures that should be taken to avoid harm to economic activities due to coast erosion and degradation are foredunes recovery, improving beach access and suitable locations for garbage.
\end{abstract}

Key-words: tourism; Xangri-lá; coastal management.

\section{Introdução}

Uma das discussões sobre meio ambiente nas zonas costeiras concentra-se na busca de conciliar o desenvolvimento do turismo e do veraneio com a preservação das características naturais deste ambiente, com a melhoria nos serviços (segurança, higiene e alimentação) e com as facilidades de acesso à praia. A administração eficaz destes aspectos possui consequências significativas para o futuro do gerenciamento da zona costeira.

A ocupação da zona costeira no Brasil é um processo ainda recente e em curso, tendo caráter espontâneo e caótico, de forma a demandar um grande esforço em ações corretivas (MORAES, 1995). O Rio Grande do Sul, por exemplo, apresenta somente $10 \%$ de sua população em municípios da zona costeira (FEPAM, 2009), mas sete dos dez municípios de maior taxa de crescimento populacional entre 1991-2000 são costeiros, todos localizados no litoral norte do Estado (IBGE, 2006). Essa população exerce uma forte pressão que gera impactos sobre os ecossistemas costeiros, podendo estes ser relacionados com a extração excessiva de recursos, contaminação industrial, degradação da qualidade da água, lançamentos de esgotos, introdução de contaminantes e descaracterização dos ambientes naturais.

Além destes impactos, a ocupação desordenada desta área, caracterizada pela substituição das dunas frontais por projetos urbanísticos, está afetando o balanço de sedimento praia-duna e levando a problemas cíclicos de manutenção das vias públicas e residências em virtude do escape de areia do sistema.

A gestão da Zona Costeira, assim como as formulações de plano de manejo de dunas, são atribuições municipais; no entanto, a maioria dos municípios não dispõe de suporte técnico para diagnosticar as causas da erosão e tampouco selecionar as técnicas de manejo mais adequadas.

Neste sentido, este trabalho tem como objetivo elucidar o panorama atual da orla marítima do município de Xangri-lá, contribuindo para o planejamento e desenvolvimento deste. 


\section{Zona Costeira e a legislação brasileira}

A Zona Costeira é um ambiente de transição ecológica, a qual desempenha importante função de ligação e de trocas entre os ecossistemas terrestres e marinhos. Abriga diversos ecossistemas, como florestas tropicais, manguezais, recifes de corais, sistema de dunas, entre outros, os quais proporcionam hábitat para muitas espécies, além de servir de defesa natural contra tempestades, inundações e erosões.

Características químicas próprias, como a elevada concentração de nutrientes, o gradiente térmico e a salinidade variável, e ainda as condições de abrigo e de suporte à reprodução e á alimentação nas fases iniciais de muitas espécies de origem marinha, classificam estes ambientes como complexos, diversificados e de extrema relevância para a sustentação da vida no mar (CICIN-SAIN; KNECHT, 1998).

No Brasil, a zona costeira se estende, na sua porção terrestre, por mais de $8.698 \mathrm{~km}$ sobre uma área de aproximadamente $388.000 \mathrm{~km}^{2}$, abrangendo uma parte terrestre com 17 Estados e mais de 400 municípios, distribuídos do norte equatorial ao sul temperado do país e uma área marinha, que corresponde ao mar territorial brasileiro, com largura de 12 milhas náuticas a partir da linha de costa (BRASIL, 2002a).

Inserida nesta região, a orla marítima pode ser definida como uma unidade delimitada pela faixa de interface entre a terra firme e o mar. Esse ambiente caracteriza-se pelo equilíbrio morfodinâmico, no qual interagem fenômenos terrestres e marinhos, sendo os processos geológicos e oceanográficos os elementos básicos de formação dos principais tipos de orla, como: costas rochosas, falésias, praias arenosas, praias de seixos, planícies lamosas, manguezais e formações recifais. A estes fatores se associam também condicionantes geográficas como o clima, a orografia e a hidrografia (BRASIL, 2002b).

A preocupação com o gerenciamento destas áreas encontra suporte no âmbito internacional na Agenda 21, Capítulo 17 e em outros documentos da Organização das Nações Unidas (ONU), e no Brasil, principalmente, com o Programa Nacional de Gerenciamento Costeiro (PNGC) e com o Projeto Orla.

A Agenda 21 é um documento propositivo e que visa, essencialmente, estimular, incentivar e orientar o processo de mudanças de mentalidade, de valores, de atitudes, de comportamentos e de procedimentos de todos os segmentos sociais (governos, empresas e entidades da sociedade civil) em relação ao nosso meio ambiente. Os principais elementos neste processo são a disseminação das informações, a educação para o desenvolvimento sustentável, a descentralização no processo de tomada de decisões, a participação efetiva das comunidades locais, a valorização da cultura regional, o planejamento de programas e ações, a cooperação e parceria, o desenvolvimento da capacidade institucional, o fortalecimento dos grupos sociais mais vulneráveis etc. No Capítulo 17, o documento trata da proteção dos oceanos e das zonas costeiras e da proteção ao uso racional e ao desenvolvimento de seus recursos vivos. Apresenta como foco o gerenciamento integrado e o desenvolvimento sustentável das zonas costeiras e marinhas, inclusive as zonas econômicas exclusivas, a proteção do meio ambiente marinho e o uso sustentável. Tem como objetivo o comprometimento dos Estados costeiros a praticar um gerenciamento integrado e sustentável das zonas costeiras e do meio ambiente marinho sob suas jurisdições nacionais. A Agenda 21 estabelece os direitos e as obrigações dos Estados e oferece a base internacional sobre a qual devem apoiar-se as atividades voltadas para a proteção e o desenvolvimento sustentável deste ambiente, bem como seus recursos.

O PNGC, cujos detalhamentos e operacionalização foram objeto da Resolução $n$. $^{\circ}$ 01/90 da Comissão Interministerial para os Recursos do Mar (CIRM), de 21 de novembro de 1990, tem como finalidade o estabelecimento de normas gerais visando à gestão ambiental da zona costeira do país, lançando as bases para a formulação de políticas, planos e programas estaduais e municipais. Este está institucionalizado em níveis nacional e estadual, caracterizando-se como um sistema com complexa estrutura e dinâmica que tem evoluído através de uma miríade de processos e controles de natureza política, econômica, institucional, ecológica, administrativa e espacial (ASMUS et al., 2006).

Como parte de PNGC, o Projeto Orla é uma iniciativa do governo federal, supervisionado pelo Grupo de Integração do Gerenciamento Costeiro (GI-GERCO) da Comissão Interministerial para os Recursos do Mar (CIRM), tendo como coordenadores a Secretaria de Qualidade Ambiental nos Assentamentos Humanos do Ministério do Meio Ambiente (SQA/MMA) e a Secretaria do Patrimônio da União do Ministério do Planejamento, Orçamento e Gestão (SPU/ $\mathrm{MP})$. O objetivo primeiro do projeto é compatibilizar as políticas ambiental e patrimonial do governo federal no trato dos espaços litorâneos sob propriedade ou guarda da União, buscando, inicialmente, dar uma nova abordagem ao uso e 
gestão dos terrenos e acrescidos de marinha como forma de consolidar uma orientação cooperativa e harmônica entre as ações e políticas praticadas na orla marítima. O Projeto Orla introduz uma ação sistemática de planejamento da ação local visando repassar atribuições da gestão deste espaço, atualmente alocadas no governo federal, para a esfera do município. Trata-se, portanto, de uma estratégia de descentralização de políticas públicas, enfocando um espaço de alta peculiaridade natural e jurídica: a Orla Marítima (BRASIL, 2002b).

No Rio Grande do Sul, cabe à Fundação Estadual de Proteção Ambiental Henrique Luiz Roessler (FEPAM) a tarefa de planejar, disciplinar, controlar e fiscalizar as atividades, empreendimentos e processos que causem ou possam causar degradação ambiental, conforme o Artigo 236 do Capítulo XVI do Código Estadual do Meio Ambiente (Lei n. ${ }^{\circ} 4.771$ de 1965), além da operação do Licenciamento Ambiental das atividades de impacto supralocal (atividades que vão modificar não só o lugar onde são desenvolvidas, mas também os arredores).

\section{A importância das dunas costeiras e seu processo de degradação}

As dunas costeiras e a vegetação natural são partes essenciais das praias arenosas. Elas ajudam a preservar as características do ambiente costeiro, protegendo-o contra a ação de ressacas e ondas de tempestades.

Devido à grande atração que as pessoas sentem em relação ao mar, o desenvolvimento urbano nos municípios litorâneos acaba por se dar o mais próximo possível da praia, alterando sua estrutura original.

Esta prática gera um processo de degradação da Zona Costeira, reportada em diversos artigos, sendo alguns destes problemas: a extração de areia das dunas, usada como aterro na construção civil para expansão imobiliária (HESP, 2002); a ação de pastagem pelo gado sobre a gramínea Panicum racemosum (principal espécie formadora e fixadora de dunas) (ROSA; CORDAZZO, 2007), a qual tem reduzido a capacidade de retenção de areia nas dunas frontais do sul do Brasil, permitindo assim que grande parte da areia migre para áreas anteriormente estabilizadas; a utilização das dunas como locais para plantações de espécies exóticas, como por exemplo, Pinus nigra na Holanda, Pinus elliottiis e Eucalyptus sp. na costa sul do Brasil (CORDAZZO et al., 2006), as quais diminuem os recursos de nutrientes do substrato, aumentam a acidificação do solo, além de alterar o equilíbrio hídrico do ambiente; a introdução acidental de espécies exóticas (resultantes da limpeza de jardins, deposição de lixo orgânico etc.) ou intencional (usadas em programas de fixação e estabilização de areia), tais como Carpobrotus chilensis, tem resultado na formação de comunidades vegetais totalmente diferentes das originais (PORTZ, 2008), alterando assim também a estrutura da fauna acompanhante.

Os efeitos da dinâmica natural, combinados com as perturbações antrópicas, podem levar a uma desestabilização da integridade do ambiente costeiro, induzindo a mudanças profundas das unidades fisiográficas, quase sempre com uma significativa redução na biodiversidade.

\section{Manejo de dunas}

Os interesses econômicos, associados à pressão pelo uso e ocupação do ambiente de dunas, geram conflitos com as suas funções ecológicas e socioculturais. Neste contexto, para garantir a sustentabilidade e a harmonia destes interesses de forma simultânea, tornam-se necessárias ações de planejamento e gestão para a integração da conservação com o desenvolvimento socioeconômico, de modo a reduzir estes conflitos.

A implementação de Programas ou Planos de Manejo de Dunas é um importante instrumento para a conservação destes ambientes, já que neste tipo de planejamento se preveem os possíveis usos do ambiente nas diferentes esferas, em um longo período de tempo.

Na prática, o manejo de dunas baseia-se nas seguintes estratégias (SOIL CONSERVATION SERVICE, 1986): conservação do sistema de dunas existentes, concedendo uma zona tampão entre as propriedades privadas e as áreas ativas de praia; recuperação das dunas com distúrbios e controle das atividades recreativas.

O programa, ao controlar as formas de utilização e apropriação do espaço de dunas, além de controlar a degradação da vegetação, destaca as implicações do Código Florestal Brasileiro (Artigo 3..$^{\circ}$ ), que considera este ambiente como Área de Preservação Permanente.

No Rio Grande do Sul, os Planos de Manejo devem seguir as orientações estabelecidas pela FEPAM por meio do Of. Circular FEPAM/PRES/12-04, sendo alvo de licenciamento ambiental. Este é um procedimento administrativo realizado pelo órgão ambiental competente, neste caso esta- 
dual, para licenciar a instalação, a ampliação, a modificação e a operação de atividades e empreendimentos que utilizam recursos naturais, ou que sejam potencialmente poluidores ou que possam causar degradação ambiental (FEPAM, 2009). No licenciamento ambiental, são avaliados impactos causados no meio ambiente, estabelecendo as condições para que a atividade ou o empreendimento cause o menor impacto possível.

No município de Xangri-lá, a primeira etapa do plano de manejo de dunas foi desenvolvida pela equipe do CECO-IG-UFRGS e teve como objetivo a caracterização ambiental e de ocupação da orla, visando à sua setorização e eleição de prioridades para intervenção. Conforme foram apontados nesta etapa (GRUBER et al., 2005), os problemas de degradação das dunas no município estão fortemente associados ao avanço da urbanização e estreitamento do sistema de duna.

\section{Processos de erosão no litoral do RS}

Os problemas de erosão na zona costeira vêm sendo discutidos em vários trabalhos, sendo atribuídos tanto a fatores naturais como antrópicos, decorrentes de eventos de longo e curto períodos (ESTEVES et al., 2002). Os processos de erosão nas zonas costeiras resultam da combinação de múltiplos fatores, como: suprimento de sedimentos, energia física induzida por ondas e variações relativas do nível do mar.

Os efeitos da erosão variam de acordo com o nível de desenvolvimento econômico da região. Em costas remotas e naturais, a erosão pode ter pouca importância e a perda de sedimentos em uma área pode significar a acreção em outra. Já em áreas mais desenvolvidas, com um grau de urbanização maior, o início ou a aceleração do processo erosivo tende a se tornar um problema maior (BIRD, 1996).

De maneira geral, entre seus efeitos indesejados constam: perdas de terrenos com valor econômico, social ou ecológico; desaparecimento de praias estreitas; perda e desequilíbrio de hábitats naturais; aumento da frequência de inundações decorrentes de ressacas; aumento da intrusão salina no aquífero costeiro; perda do valor paisagístico e do potencial turístico da região e exposição das zonas costeiras à energia dos oceanos e riscos aos moradores.

Evidências de erosão costeira no Rio Grande do Sul foram compiladas em 2004 por Dillenburg et al., sendo apontados, basicamente, três métodos de avaliação: a) análises estratigráficas e morfodinâmicas, de longo período, das barreiras costeiras, o que vem demonstrando que a erosão costeira é uma continuidade da evolução geológica nos últimos $5 \mathrm{ka}$, ocorrendo principalmente na metade sul, a partir de suaves projeções costeiras. As evidências estão na exposição de lamas lagunares e turfas ao longo de $15 \mathrm{~km}$ na área da praia do Hermenegildo (litoral sul) e $60 \mathrm{~km}$ na praia de Bujuru - Farol da Conceição (litoral médio);

b) mapeamento anual da linha de costa através do Sistema de Posicionamento Global Diferencial (DGPS). Este método, adotado desde 1997, representa uma curta escala temporal. Linhas de costa obtidas em 2000, quando comparadas com linhas de costa obtidas através da digitalização de mapas topográficos de 1975 em escala de 1:50.000, indicam que aproximadamente $81 \%$ das praias estão em erosão, $12 \%$ estão estáveis e 7\% estão em acreção;

c) levantamentos altimétricos de perfis praiais têm sido executados em poucos locais e distantes uns dos outros, desde o início dos anos 1990, e, consequentemente, seus resultados refletem um comportamento local e de curto período da linha de costa. Como exemplo, as análises de perfis de praia de 1996 a 1999 na praia de Lagamarzinho (Litoral Médio do RG) mostram uma média de 1 $\mathrm{m} /$ ano de retração.

Outro fator observado na costa do Rio Grande do Sul foi a ocorrência de concentração de energia de ondas por refração nos locais de elevada taxa de erosão; neste exemplo, enquadram-se a região do Farol da Conceição (litoral médio) e a região ao norte do Chuí (litoral sul).

A avaliação crítica dos dados até hoje publicados sobre a erosão da linha de costa do Rio Grande do Sul sugere fortemente que o balanço negativo no estoque de sedimentos costeiros, em escalas de longo e curto período, é a principal causa da erosão (DILLENBURG et al., 2004).

Em 1999, foram publicados mapas classificando a costa do Rio Grande do Sul em praias em erosão, estáveis ou em acreção. Considerou-se estável o trecho da costa que apresentou uma retração ou acreção de até $25 \mathrm{~m}$ no período entre 1975 e 2000; por outro lado, foram considerados em erosão os trecho que apresentaram retração acima de $25 \mathrm{~m}$ e em acreção os que apresentaram uma progradação acima de 25 m (TOLDO JR. et al., 1999). 
No litoral norte, no setor entre Tramandaí e Pinhal, predominam praias em erosão, sendo estas observadas nos trechos onde ocorre um incremento no fluxo de energia dentro da zona de surfe ao longo da praia e os trechos em acreção são observados nos locais onde ocorrem mudanças no alinhamento da linha de praia.

O setor entre Tramandaí e Torres alterna áreas em erosão e áreas em acreção possivelmente devido às suas condições de praias intermediárias, mais sensíveis a episódios de erosão (TABAJARA, 2005).

\section{Caso de estudo: município de Xangri-lá}

A costa do Rio Grande do Sul (RS) desde Torres, ao norte, até a desembocadura do Arroio Chuí, ao sul, é constituída por uma ampla planície costeira com cerca de 620 $\mathrm{km}$ de extensão e até $120 \mathrm{~km}$ de largura, onde um sistema de barreiras arenosas aprisiona um gigantesco sistema lagunar (Lagunas dos Patos e Mirim) e uma série de outros corpos de água isolados ou interligados com o mar por intermédio de canais estreitos e rasos (VILLWOCK, 1984).

Sua formação, durante o Período Quaternário, desenvolveu-se a partir da justaposição lateral de quatro sistemas deposicionais do tipo laguna-barreira, cuja formação foi controlada pelas flutuações do nível do mar durante o Quaternário (barreira-laguna I, II e III de idade Pleistocênica e sistema IV, que iniciou sua formação há cerca de $7 \mathrm{ka}$ ), constituindo uma sucessão de terraços marinhos e lagunares (VILLWOCK, 1984). A atual linha de costa da planície costeira do Rio Grande do Sul apresenta uma orientação geral Nordeste-Sudoeste com praias arenosas retilíneas e contínuas, predominantemente dominadas por ondas.

A ocupação efetiva do litoral norte começou no século XVIII, com a chegada dos primeiros colonizadores de origens portuguesa e açoriana. A economia na região era baseada na agricultura e pecuária extensivas, além da pesca, sendo suas sedes e atividades implantadas nas áreas mais continentais.

Com a fixação de colonos alemães e italianos, passou a ocorrer a inserção de novos agentes econômicos. As transformações começaram a ocorrer com a divulgação das propriedades terapêuticas dos banhos de mar, impulsionando a instalação de pequenos chalés e pousadas por pequenos empresários. Desta forma, a orla marítima começou a ser valorizada para o uso ocasional nos meses de verão (STROHAECKER, 2007).
Porém, o acesso ao litoral norte permaneceu precário até a década de 1920 (SOARES, 2000 apud STROHAECKER, 2007), quando começou o trabalho de arborização, promovido pelo Estado, junto às lagoas costeiras e à orla marinha, para a fixação das dunas, com a finalidade de viabilizar a ocupação e o desenvolvimento da região.

Os investimentos estatais nas primeiras décadas do século XX (rodovias, sistema de transporte lacustre-ferroviário, arborização e fixação de dunas nos balneários) foram importantes balizadores para o desenvolvimento da região. As melhorias no acesso permitiram que outros agentes econômicos passassem a investir no litoral norte, principalmente no setor imobiliário (STROHAECKER, 2007).

Atualmente, o litoral norte do Rio Grande do Sul é integrado por 19 municípios, com economia preponderantemente associada às atividades de turismo e de veraneio, o que confere à região características de grande variação sazonal da população e intensa urbanização.

O município de Xangri-lá possui uma população predominantemente urbana (95\%); no entanto, menos de $20 \%$ dos domicílios são ocupados permanentemente, sendo este valor aumentado significativamente nos meses de verão (STROHAECKER, 2007). A atividade econômica deste município é voltada principalmente para o comércio sazonal nos meses de verão, apresentando séria carência em infraestrutura (abastecimento de água, coleta e destino do esgoto cloacal, destinação final dos resíduos sólidos), equipamentos e recursos humanos nos setores de saúde e educação.

Como consequências ambientais, frente às principais atividades e às características de seu desenvolvimento, temos: desmatamento, contaminação de águas e solos; geração de resíduos sólidos e efluentes domésticos; conflitos de uso do solo (ocupação irregular); número significativo de domicílios para uso ocasional; exploração do subsolo (destruição dos sambaquis e dunas); alteração da fauna e flora; alteração dos costumes da população permanente e risco de ocorrência de poluição acidental (cargas tóxicas) pela presença do terminal de carga e descarga de petróleo e derivados da Petrobrás.

\section{Metodologia}

Neste estudo, foi realizada uma investigação dos problemas e dos conflitos existentes entre o uso e a preservação da orla marinha através de observações de campo cíclicas, além do levantamneto de perfis de topografia e de vegetação. 
Os perfis de topografia e de vegetação foram traçados a cada $1 \mathrm{~km}$, abrangendo toda orla do município, conforme a Figura 2, sendo estes realizados em dezembro de 2005 e 2006. Os perfis topográficos bidimensionais foram obtidos por meio de nivelamento geométrico, utilizando-se como ferramentas um nível topográfico, mira e trena, sendo estes perfis amarrados a pontos de referência fixos, tais como postes de luz existentes na Avenida Beira-Mar. Para a amarração dos perfis de praia, foi estabelecido o valor arbitrário de $3 \mathrm{~m}$ como Datum vertical. Os perfis de cobertura vegetal foram realizados através de observação visual em perfis transversais à praia associados a quadrados de $1 \mathrm{x} 1 \mathrm{~m}$, usando a mesma base dos perfis topográficos como referencial de nível.

\section{Caracterização e situação atual do sistema de dunas}

A orla do município de Xangri-lá é caracterizada por apresentar um sistema de dunas frontais contendo até três cristas de dunas alinhadas à linha de costa. São cordões de dunas descontínuos, com topografia irregular e muito segmentados. A altura máxima verificada para o sistema eólico foi de 3,20 m (P6), com largura variando entre $13 \mathrm{e}$ $40 \mathrm{~m}$ (média de $28 \mathrm{~m}$ ). Estas características representam um sistema de dunas com grande fragilidade frente a eventos de tempestade. Dois pontos principais levam a esta fragilidade: a segmentação e a largura da duna, ou seja, quanto mais

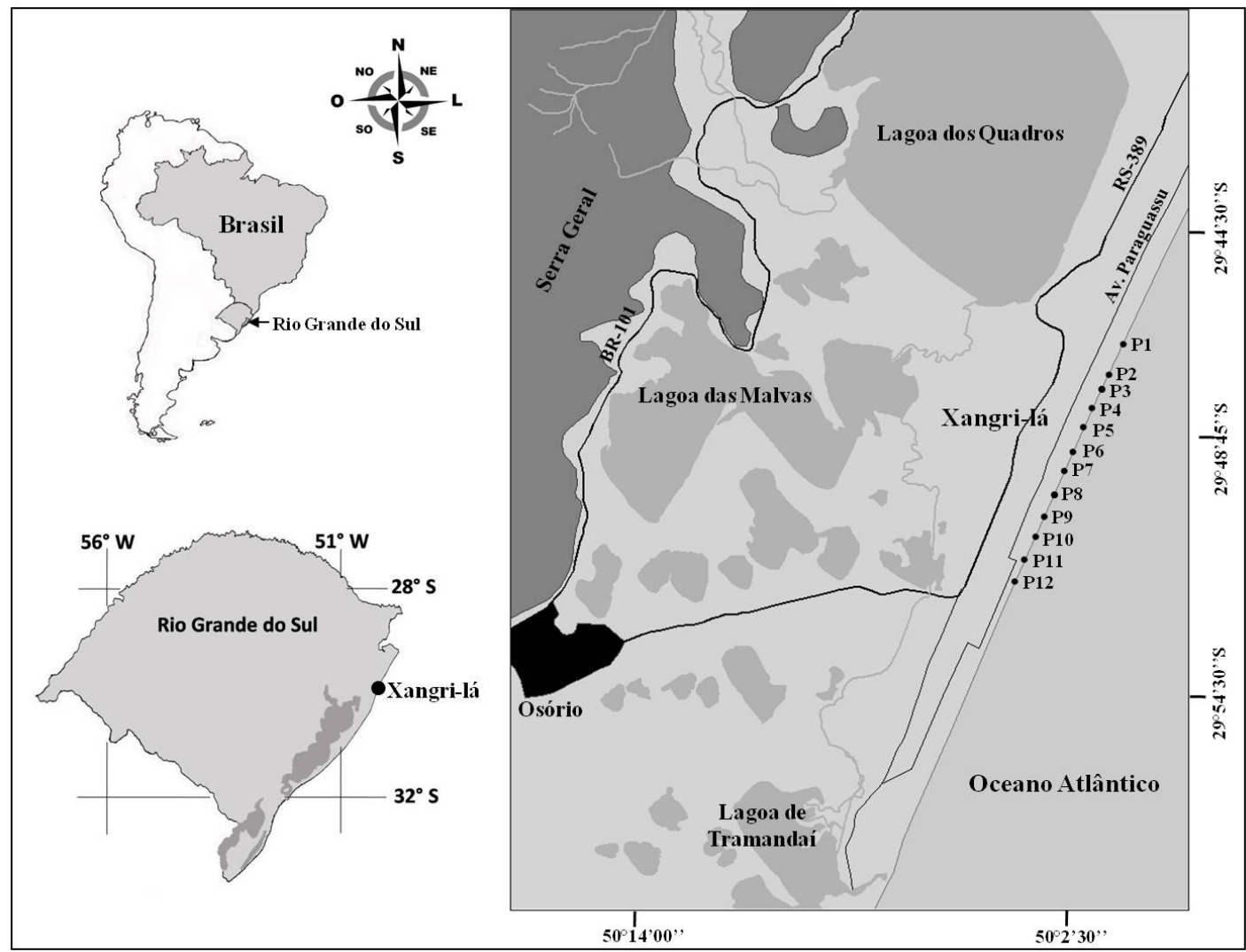

FIGURA 1 - LOCALIZAÇÃO DA ÁREA DE ESTUDO E DOS PONTOS DE AMOSTRAGEM. 
segmentada estiver a duna frontal maior será a penetração de ondas de tempestade para o interior do sistema, e quanto menor a largura do sistema de dunas menor será o estoque de sedimentos. A característica de segmentação das dunas ocorre principalmente pelo elevado número de sangradouros presentes na área, uma consequência das edificações e pavimentação das ruas que reduz desta forma a infiltração da água pluvial, aumentando a vazão e desta forma rompendo o sistema de dunas. A reduzida largura do sistema de dunas é, também e principalmente, induzida pela urbanização que se estabeleceu na pós-duna, fenômeno que provocou essa drástica redução.

Perturbações naturais, como ressacas e ondas de tempestades, eventualmente podem causar alterações no sistema de dunas; porém, a resiliência natural do sistema tende à recuperação. No entanto, entre os anos de 2005 e
2006, durante o monitoramento para o projeto de Manejo de Dunas no município Xangri-lá, foi registrado um evento meteo-oceanográfico catastrófico, produzido pela passagem de um ciclone extratropical, desencadeando um processo acentuado na ação de erosão, sendo os processos de reconstrução ineficientes neste período, de acordo com os perfis topográficos realizados (Fig. 3).

A cobertura vegetal nos perfis foi considerada de moderada a escassa, associada às morfologias erosivas dos corredores de vento e das bacias de deflação (Fig. 3). A diminuição da vegetação no sentido da crista ocasionou uma maior mobilização do sedimento e, com isso, maior transporte deste em direção ao continente, causando acumulação na Avenida Beira-Mar e nas residências próximas. Em virtude deste problema, o município de Xangri-lá tem apresentado, nos últimos anos, problemas constantes de
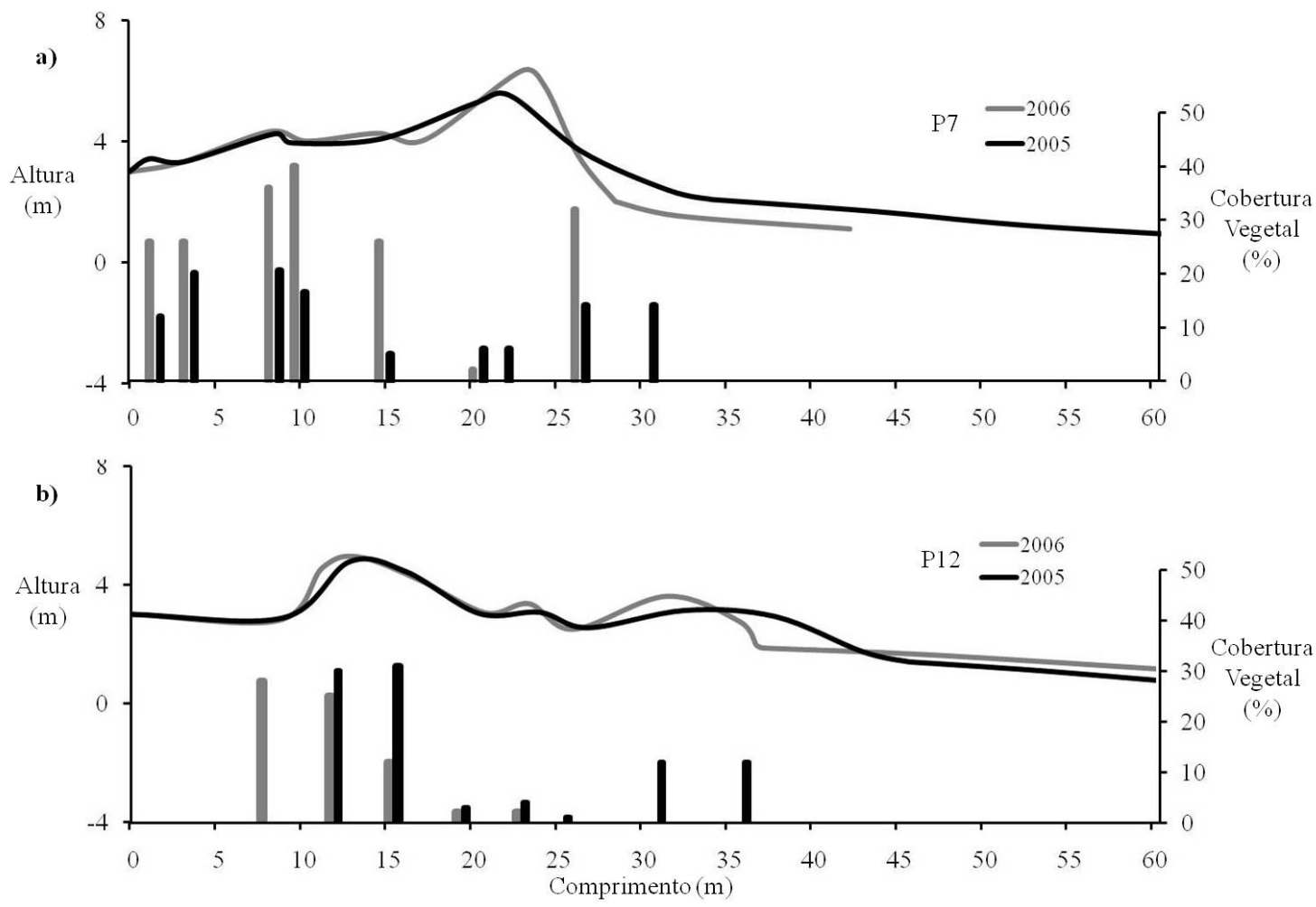

FIGURA 2 - PERFIS TOPOGRÁFICOS E DE VEGETAÇÃO. A) P7. B) P12. O EIXO À ESQUERDA REPRESENTA A ALTURA DAS DUNAS EM METROS. O EIXO À DIREITA REPRESENTA A PORCENTAGEM DE COBERTURA VEGETAL. O EIXO X REPRESENTA O COMPRIMENTO DO PERFIL TOPOGRÁFICO. 

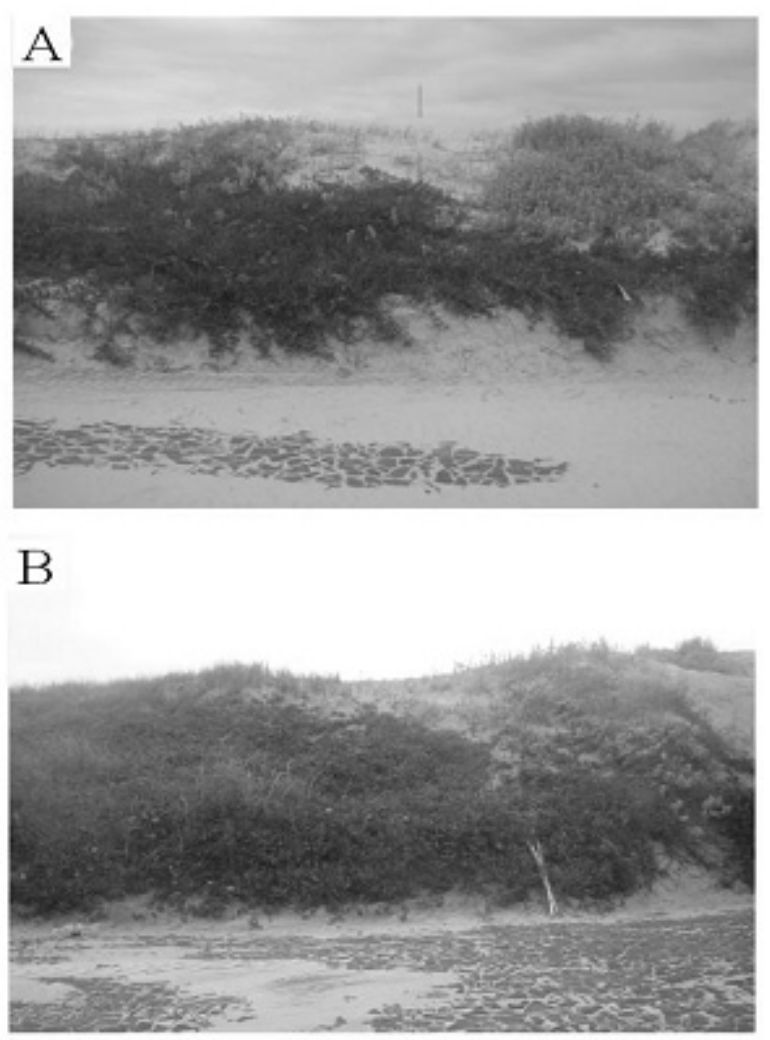

FIGURA 3 - FOTOGRAFIA DO PERFIL 6. A: FOTO DE 2006. B: FOTO DE 2005.

manutenção das vias públicas, provocando grandes prejuízos, principalmente nas áreas desprovidas de dunas ou associadas aos sangradouros.

Outro fator negativo quando ocorre a diminuição da vegetação é a acentuação da tendência erosiva na morfologia das dunas frontais até o seu completo desaparecimento.

$\mathrm{O}$ sistema de dunas apresenta baixa diversidade em espécies vegetais - sendo que $50 \%$ dos pontos monitorados apresentaram somente três espécies -, além de não apresentar um padrão de distribuição similar.

A espécie de Panicum racemosum é a planta dominante em todos os perfis monitorados. Esta é uma das espécies pioneiras que leva a um acúmulo de areia e, mesmo com a ocorrência de tempestades e consequente erosão, permanecem pedaços destas plantas, que são capazes de rebrotar e, assim, recolonizar a duna. Juntamente com esta, predominam também nos perfis as espécies Senecio crassflorus e Hydrocotyle bonariensis. Na porção frontal e no topo da duna, a predominância foi das duas primeiras. Já na porção posterior da duna a distribuição foi equitativa.

De modo geral, na pós-duna a cobertura vegetal é mais densa, pois se localiza em uma área sem contato direto com os efeitos das tempestades. Esta, porém, apresenta-se em estado avançado de degradação por pisoteio como consequência de aberturas de caminhos para os acessos à praia. As dunas mais estáveis são justamente aquelas com a melhor distribuição e diversidade de espécies vegetais, desde a face marinha até a pós-duna (perfis P1, P7 e P11).

A presença da planta Carpobrotus chilensis (onze horas), originária da África do Sul, muito adaptada às regiões costeiras, chegando ao ponto de ser considerada uma praga em muitos lugares, como na Califórnia, tem mostrado um rápido aumento na dispersão e no volume ao longo de toda orla (Fig. 4). A facilidade de adaptação desta planta deve ser considerada preocupante, principalmente pelo fato dela causar significativa perturbação ecológica em todos os ambientes em que se estabeleceu, com diversos prejuízos ecológicos à flora e à fauna destes lugares (CORDAZZO et al., 2006).

Não foi constatada a presença de dunas embrionárias, o que reforça a evidência de um balanço negativo de areia no sistema eólico.

\section{Conflitos de ocupação}

A fragilidade dos ecossistemas costeiros e a rapidez da ocupação tornam as ações de planejamento (preventivo e corretivo) essenciais no litoral, sendo que duas situações requerem atenção prioritária. A primeira diz respeito às áreas próximas dos centros urbanos já estabelecidos, onde as atividades de veraneio e a progressiva concentração da população de baixa renda nas periferias respondem pela agressividade da expansão urbana, e a segunda é a criação de novos centros urbanos em áreas pouco ocupadas, em geral vinculadas a atividades específicas (industriais, turísticas, portuárias etc.) (MORAES, 1995).

Em Xangri-lá, a urbanização já é intensa e os problemas de planejamento urbano tendem a aumentar, principalmente nos meses de verão, com o crescimento sazonal da população em virtude do turismo e do veraneio. Para se entender este crescimento, na baixa temporada o município apresenta população entorno de 9.700 habitantes, sendo este número aumentado para cerca de 200 mil nos meses de janeiro e fevereiro. 
Dentre os conflitos de ocupação envolvidos na área de estudo, destaca-se a posição da urbanização dentro do perfil transversal à praia, principalmente com a presença de calçadão à beira-mar, pois este influencia diretamente na área e na largura da duna e nos níveis de cobertura impermeável.

De forma geral, nos locais onde a largura da duna é superior a $30 \mathrm{~m}$ a função da duna frontal é mantida, enquanto que nas áreas onde parte ou toda a duna frontal foi substituída por ruas ou praças a capacidade de estabilização do sedimento pela vegetação é comprometida, facilitando a fuga de areia para o interior das vias. Esta característica leva a uma preocupação com o sistema de dunas de Xangri-lá, que apresenta a média na largura de dunas de $28 \mathrm{~m}$.

Considerando o padrão urbanístico homogêneo do município, no qual o estágio de ocupação humana é do tipo horizontal padrão, abrangendo toda a extensão da orla e posicionado muito próximo do sistema de dunas, pode-se inferir que este seja o fator que determina o comportamento das dunas.

Em estudos anteriores para o litoral norte do Rio Grande do Sul, já se constatou como principal condicionante das características morfológicas da faixa de dunas a pressão de uso antrópico (GRUBER et al., 2005; ESTEVES et al., 2003), ressaltando a importância de se eliminar os conflitos de uso e ocupação nestes locais.

\section{Degradações pela recreação}

Alguns dos resultados da pressão recreativa sobre o sistema de dunas são os danos do pisoteio sobre a vegetação e os efeitos ecológicos desse tipo de impacto (BOWLES, 1982).

Neste sentido, foram identificados, na área de dunas do município, locais de travessia de carros e motos. Estas atividades, direta ou indiretamente, afetam significativamente a vegetação das dunas, pois o tráfego contínuo propicia o aparecimento de trilhas sobre a vegetação responsável pela fixação das dunas.

A presença de trilhas formadas pelo pisoteio de pessoas é outro problema encontrado no ambiente, devido à utilização das dunas como via de acesso para chegar à praia. Este processo provoca um alto grau de compactação do terreno, apresentando alta resistência à penetração (ROSA, 2007), podendo dificultar uma nova coloniza- ção. Desta forma, é possível considerar a ocorrência de uma descaracterização de todo o ambiente, o que acaba facilitando a erosão e induzindo a uma grande área com perda da cobertura vegetal e, consequentemente, podendo iniciar a formação de blow-outs (STOTT et al., 1993), o que representa sérios riscos não só à flora adjacente como também à fauna acompanhante.

$\mathrm{Na}$ literatura são encontrados diversos relatos dos efeitos causados pelo pisoteio sobre a vegetação de dunas, como a compactação do solo e a redução da cobertura vegetal (CARLSON; GODFREY, 1989); a redução da produção de biomassa (LIDDLE, 1975); a redução do número de espécies florescendo (HYLGAARD, 1980); a perda da biodiversidade (ANDRÉS-ABELLAN et al., 2005) e a criação de caminhos.

Contudo, os impactos negativos nestas áreas são uma consequência inevitável da recreação, pois mesmo os mais conscientes visitantes deixam marcas e perturbações à vida destes ambientes sem intenções reais de fazê-lo (LEUNG, 2000).

\section{Deposição de lixo}

O lixo marinho é definido como qualquer resíduo sólido (plástico, isopor, borracha, vidro, metal, tecido, entre outros materiais) que tenha sido introduzido no ambiente marinho ou costeiro por qualquer fonte (COE; ROGERS, 1997). Do ponto de vista científico, o problema do lixo vem sendo tratado como um dos principais problemas relacionados à poluição marinha nas últimas décadas (GOLDBERG, 1995, IVAR DO SUL, 2007), sendo suas consequências reportadas em áreas costeiras e marinhas em todo mundo. Entre elas destacam-se os danos à biota (LAIST, 1987), às atividades de pesca (NASH, 1992) e a perda da qualidade estética da praia (ARAÚJO; COSTA, 2006), que pode resultar em prejuízos econômicos associados à indústria do turismo (NOLLKAEMPER, 1994) e limpeza pública.

Nas praias de Xangri-lá, foram amostrados os resíduos em três diferentes oportunidades, abrangendo condições meteorológicas (estação do ano) e de ocupação distintas: (1) fevereiro - período de veraneio e turismo intenso, (2) abril - período de outono, caracterizado pelo turismo fraco e (3) agosto - período de inverno, praticamente sem turismo (PORTZ, 2010). 
TABELA 1 - TOTAL DE ITENS AMOSTRADOS NOS PERFIS PRAIA E DUNA NOS DIFERENTES MESES

\begin{tabular}{|c|c|c|}
\hline & Meses & Itens $\mathrm{m}^{-1}$ \\
\hline \multirow{3}{*}{ 2. } & Fevereiro & 9.93 \\
\hline & Abril & 2.50 \\
\hline & Agosto & 1.55 \\
\hline \multirow{3}{*}{ 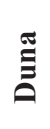 } & Fevereiro & 9.34 \\
\hline & Abril & 4.58 \\
\hline & Agosto & 2.90 \\
\hline
\end{tabular}

Este estudo demonstrou que o lixo presente no ambiente marinho é o resultado de uma inadequada manipulação ou eliminação de resíduos descartados, tendo como destino a praia. A redução observada na região da pós-praia de fevereiro para agosto em decorrência da diminuição de atividade de turismo e veraneio mostrou que a principal fonte de resíduos nas praias é em decorrência do turismo e do veraneio.

O péssimo aspecto estético conferido pelo acúmulo de resíduos sólidos na praia, principal fonte econômica para este município, pode levar a sérias perdas econômicas, como diminuição no índice de emprego e da renda.

\section{Ações de manejo}

Apesar das experimentações no sentido de recuperação das dunas terem avançado nos últimos anos no Brasil, ainda existe uma incerteza e pouca informação sobre estratégias bem sucedidas.

Considerando as condições atuais do sistema de dunas do município, uma das alternativas para sua recuperação e, consequentemente, para reduzir os efeitos da erosão seria a utilização de métodos não estruturais. Estes métodos se baseiam em ações onde não se utilizem estruturas rígidas como espigões, quebra-mar e assemelhados.

Sendo o posicionamento da urbanização o fator preponderante no impacto sobre o sistema de dunas, são de extrema necessidade as ações de controle e ordenamento dos acessos à praia, restringindo os caminhos de pedestres e veículos e outras atividades sobre o sistema de dunas. Todos os programas internacionais preconizam o controle das atividades recreativas nas áreas de uso intensivo das praias, a fim de evitar a destruição das dunas e sua vegeta- ção. Isto pode ser impedido em grandes extensões, a partir da instalação de cercas na periferia do campo de dunas, direcionando os acessos transversais ao vento dominante (no RS, vento de nordeste) e a construção de passarelas por cima das dunas ou estrados de madeira pelo chão.

Com relação à diminuição da vegetação e consequente escape de areia para as avenidas e para as residências próximas das dunas, são indicadas ações que colaborem com a permanência da areia sobre o sistema, como a colocação de cobertura morta (cascas de árvores ou mesmo galhos secos, sem presença de sementes que poderão germinar) e posterior plantio de vegetação nativa (Panicum racemosum e Senecio crassflorus).

A erosão nas áreas adjacentes aos sangradouros pode ser amenizada com o preenchimento das dunas adjacentes, importando sedimento similar de outros locais e, após, realizar o plantio de vegetação capaz de estabilizar a duna.

Paralelamente a todas estas ações e para o sucesso do plano de gestão, é necessária uma estratégia de informações para a comunidade e de programas de sensibilização pública, pois somente preservamos e colaboramos com ações de melhoria quando compreendemos a real necessidade destas.

\section{Considerações finais}

O levantamento da situação atual das dunas do município de Xangri-lá e dos conflitos existentes caracteriza a orla como intensamente urbanizada, apresentando o sistema de dunas com características naturais em apenas algumas áreas.

A metodologia utilizada para o levantamento atual das condições da orla marítima do município, que abrange tanto observações cíclicas de campo quanto levantamentos de dados topográficos e de vegetação, auxilia de forma integrada na identificação dos conflitos, indicando áreas e características que tornam o sistema frágil.

O conhecimento das características principais do sistema de dunas auxilia os gestores no estabelecimento de critérios a serem utilizados no manejo das dunas. A identificação da vegetação predominante, por exemplo, indica qual a espécie que se torna mais suscetível ao sucesso do plantio frente ao manejo de dunas, assim como a identificação do perfil da duna leva ao estabelecimento das características principais a serem respeitadas na necessidade de recuperar um trecho do sistema de dunas não mais existente. 
Em geral, no litoral gaúcho, a manutenção e a recuperação das dunas costeiras são exclusivamente de responsabilidade do órgão municipal, ao contrário do que ocorre em outras locais, como em Nova Jersey-USA (CONWAY; NORDSTROMA, 2003), onde a população residente possui papel fundamental neste processo.

As municipalidades são responsáveis pela elaboração do Plano de Manejo de Dunas e também pela sua execução. Porém, por falta de servidores especializados nesta prática, falta de recursos e muitas vezes por descaso por parte das administrações, este não é colocado em prática. No Estado, além da população residente não contribuir com estas práticas, a presença de resíduos sólidos na orla provenientes da inadequada manipulação ou eliminação por parte dos frequentadores contribui para o péssimo aspecto estético conferido pelo acúmulo de resíduos sólidos na praia.

Somando-se os processos de erosão atuantes na costa do Rio Grande do Sul à carência de ações que minimizem este processo e à falta de comprometimento dos usuários da praia, desenvolve-se um cenário de degradação ambiental e de descaracterização cênica que se opõe com a situação econômica deste município, que depende diretamente do turismo e do veraneio.

Quando defrontamos o processo descrito acima com os princípios oriundos da Agenda 21, identifica-se uma carência na disseminação das informações para a população local, na educação para o desenvolvimento sustentável e na participação efetiva das comunidades locais nos processos de preservação das características naturais. Outro fator relevante nesta análise é o lento desenvolvimento da capacidade institucional frente a estes problemas, refletido na falta de qualificação do funcionalismo e de ações concretas.
Neste sentido, a falta de comprometimento da gestão municipal frente ao cenário de erosão já mencionado na literatura alerta para um futuro onde esta erosão, hoje ainda em estágio inicial, não poderá ser contida apenas com os métodos citados anteriormente (não estruturais), tornando o processo de recuperação mais lento e oneroso. Um ponto positivo das ações do município é o estabelecimento de cooperação e parceria com instituições de ensino na busca de minimizar os efeitos da falta de qualificação do funcionalismo.

De forma geral, a falta de gestão das zonas costeiras está contribuindo irreversivelmente para a degradação progressiva do patrimônio natural do Estado do Rio Grande do Sul, incluindo a paisagem cênica, que é um dos seus elementos essenciais e do qual os municípios dependem diretamente como fonte de renda. Promover a compreensão e a conservação para que se perpetue este ambiente depende diretamente deles, os gestores costeiros, e para garantir que as atividades de turismo e o veraneio se mantenham é importante compreender não só a situação e os processos atuais, mas também aqueles processos ativos no recente passado geológico, como é o caso da erosão.

Além de todos os desafios e necessidades apontados com relação à manutenção das atividades de turismo e de veraneio na zona costeira, deve-se ter explícito que estas são essenciais para os municípios e sempre gerarão mudanças ambientais.

Por fim, a questão primordial - com relação à legislação e aos Planos de Manejo de Dunas - encontra-se na exigência de se formular os planos sem a necessidade de executá-los.

\section{Referências}

ANDRÉS-ABELLÁN, M.; ÁLAMO, J.; LANDETE-CASTILLEJOS, T.; LÓPEZ-SERRANO, F.; GARCÍA-MOROTE, F.; DEL CERRO-BARJA, A. Impacts of Visitors on Soil and Vegetation of the Recreational Area "Nacimiento Del Río Mundo" (Castilla-La Mancha, Spain). Environmental Monitoring and Assessment, v. 101, n. 1-3, p. 55-67, 2005.

ARAÚJO, M. C. B.; COSTA, M. F. The Significance of Solid Wastes with Land-Based Sources for a Tourist Beach: Pernambuco, Brazil. Pan-American Journal of Aquatic Sciences, v. 1, n. 1, p. 28-34, 2006.
ASMUS, M.; KITZMANN, D.; LAYDNER, C.; TAGLIANI, C. R. A. Gestão costeira no Brasil: instrumentos, fragilidades e potencialidades. Revista de Gestão Costeira Integrada - Edição especial: Políticas Públicas, v. 5, p. 52-57, 2006.

BIRD, E. C. F. Beach Management. New York: Wiley, 1996.

BOWLES, J. M.; MAUN, M. A. A Study of the Effects of Trampling on the Vegetation of Lake Huron Sand Dunes at Pinery Provincial Park. Biological Conservation, v. 24, p. 273-283, 1982. 
BRASIL. Lei n. 4.771, de 1965. Art. 3º, Código Florestal Brasileiro. D.O.U. de 16.9.1965.

Lei n. 7.661, de 16 de maio de 1988. Institui o Plano Nacional de Gerenciamento Costeiro e dá outras providências. Brasília: D.O.U. de 18.5.1998.

. Resolução n. 01/90 da Comissão Interministerial para os Recursos do Mar (CIRM), de 21 de novembro de 1990.

. Avaliação e ações prioritárias para a conservação da biodiversidade da zona costeira brasileira. Brasília: MMA/ SBF, 2002a.

Ministério do Meio Ambiente. Projeto Orla: Fundamentos para Gestão Integrada. Brasília: MMA/SQA, Brasília: MP/SPU, 2002b.

CARLSON, L. H.; GODFREY, P. J. Human Impact Management in a Coastal Recreation and Natural Area. Biological Conservation, Nortolk, v. 49, p. 141-156, 1989.

CICIN-SAIN, B., KNECHT, R. W. Integrated Coastal and Ocean Management: Concepts and Practices. Washington, D.C.: Island Press, 1998.

CÓDIGO ESTADUAL DO MEIO AMBIENTE. Lei $n$. 11.520, de 03 de agosto de 2000. Institui o Código Estadual do Meio Ambiente do Estado do Rio Grande do Sul e dá outras providências. Artigo n. 236 do Cap. XVI. Expediente n. 3600-08.01/98-5.

COE, J. M.; ROGERS, D. B. Marine Debris: Sources, Impacts and Solutions. Nova York: Springer-Verlag, 1997.

CONWAY, T. M.; NORDSTROMA, K. F. Characteristics of Topography and Vegetation at Boundaries between the Beach and Dune on Residential Shorefront Lots in Two Municipalities in New Jersey, USA. Ocean \& Coastal Management, v. 46, p. $635-648,2003$.

CORDAZZO, C. V.; PAIVA, J. B.; SEELINGER, U. Guia Ilustrado: plantas das dunas da costa sudoeste atlântica. Pelotas: Editora USEB, 2006.

DILLENBURG, S. R.; ESTEVES, L. S.; TOMAZELLI, L. J. A Critical Evaluation of Coastal Erosion in Rio Grande do Sul, Southern Brazil. Anais da Academia Brasileira de Ciências. v. 76, n. 3, p. 611-623, 2004.

ESTEVES, L. S.; SILVA, A. R. P.; AREJANO, T. B.; PIVEL, M. A. G.; VRANJAC, M. P.; BARLETTA, R. C. Coastal Development and Human Impacts along the Rio Grande do Sul Beaches, Brazil. Journal of Coastal Research, v. 35, p. 548-556, 2003.
ESTEVES, L. S.; TOLDO Jr., E. E.; DILLENBURG, S. R.; TOMAZELLI, L. J. Long- and Short- Term Coastal Erosion in Southern Brazil. Journal of Coastal Research, v. 36, p. 273-282, 2002.

FEPAM, 2009. Fundação Estadual de Proteção Ambiental Henrique Luiz Roessler - RS. Programas e projetos: Programa de Gerenciamento Costeiro - GERCO. Disponível em: $<$ http://www.fepam.rs.gov.br/programas/programa_gerco. asp>. Acesso em: jan. 2010.

GOLDBERG, E. D. Emerging Problems in the Coastal Zone for the Twenty-First Century. Marine Pollution Bulletin, v. 31, n. $4-12$, p. $152-158,1995$.

GRUBER, N. L. S.; CORRÊA, I. C. S.; TABAJARA, L. L.; SILVA, C. R. C.; SOUZA, R. R.; SILVA, D. C.; UGRI A.; BORGES, C. L. L. Diagnóstico de vulnerabilidade dos campos de dunas frontais do Município de Xangri-lá-RS como subsídio ao plano de manejo. Centro de Estudos de Geologia Costeira e Oceânica CECO/IG/UFRGS e Prefeitura Municipal de Xangri-lá. Documento técnico, 2005.

HESP, P. A. Coastal Sand Dunes: Form and Function. CDVN Technical Bulletin n. 4. Massey University, 2002.

HYLGAARD, T. Recovery of Plant Communities on Coastal Sand-Dunes Disturbed by Human Trampling. Biological Conservation, v. 19, n. 1, p.15-25, 1980.

IBGE, Instituto Brasileiro de Geografia e Estatística. Estatísticas: Censos. 2006. Disponível em <http://www.ibge.gov.br>. Acesso em: nov. 2009.

IVAR DO SUL, J.; COSTA, M. F. Marine Debris Review for Latin America and the Wider Caribbean Region: From the 1970s until Now, and Where do We Go From Here? Marine Pollution Bulletin, v. 54, p. 1087-1104, 2007.

LAIST, D. W. Overview of the Biological Effects of Lost and Discarded Plastic Debris in the Marine Environment. Marine Pollution Bulletin, v. 18, p. 319-326, 1987.

LEUNG, YU-FAI.; MARION JEFFREY, L. Recreation Impacts and Management in Wilderness: a State-of-Knowledge Review. In: COLE, D. N.; McCOOL, S. F.; BORRIE, W. T.; OÂ'LOUGHLIN, J. Wilderness Science in a Time of Change Conference-Volume 5: Wilderness ecosystems, threats, and management. Missoula, MT. Proceedings RMRS-P-15-VOL-5. Ogden, UT: U.S. Department of Agriculture, Forest Service, Rocky Mountain Research Station, p. 23-48, 2000.

LIDDLE, M. J.; GREIG-SMITH, P. A Survey on Tracks and Paths in a Sand Dune Ecosystem. II. Vegetation. Journal of Applied Ecology, v. 12, p. 909-930, 1975. 
MORAES, A. C. R. Os impactos da política urbana sobre a zona costeira. Brasília: Ministério do Meio Ambiente, dos Recursos Hídricos e da Amazônia Legal, Secretaria de Coordenação dos Assuntos do Meio Ambiente, MMA, 1995.

NASH, A. D. Impacts of Marine Debris on Subsistence Fishermen. An Exploratory Study. Marine Pollution Bulletin, v. 24, p. 150-156, 1992.

NOLLKAEMPER, A. Land-Based Discharges of Marine Debris: from Local to Global Regulation. Marine Pollution Bulletin, v. 28, p. 649-652, 1994.

PORTZ, L. Contribuição para o estudo do manejo de dunas: caso das praias de Osório e Xangri-Lá, Litoral Norte do Rio Grande do Sul. Dissertação (Mestrado em Geociências) UFRGS. Porto Alegre, 2008.

; MANZOLLI, R. P.; IVAR DO SUL, J. A. Marine Debris on Rio Grande do Sul North Coast, Brazil: Spatial and Temporal Patterns. Journal of Integrated Coastal Zone Management. In press. Available in: <http://aprh.pt/rgci/pdf/ rgci-187_Portz.pdf>. 2010.

ROSA, L. S.; CORDAZZO, C. V. Perturbações antrópicas na vegetação das dunas da praia do cassino (RS). Cadernos de Ecologia Aquática, v. 2, n. 2, p. 1-12, 2007.
SOIL CONSERVATION SERVICE. Beach Dunes: Their Use and Management. Sydney: Soil Conservations Service of NSW, 1986. $32 \mathrm{p}$.

STOTT, T.; HINDSON J.; CRUMP R. Sand Dunes - A Practical Coursework Guide. Shrewsbury: Field Studies Council Publications, 1993.

STROHAECKER, T. M. A urbanização no Litoral Norte do estado do Rio Grande do Sul: contribuição para a gestão urbana ambiental no município de Capão da Canoa. Tese (Doutorado Ciências) - UFRGS. Porto Alegre, 2007.

TABAJARA, L. L. C. A. Controle morfodinâmico na formação e desenvolvimento das dunas frontais no Litoral Norte do Rio Grande do Sul. In: CONGRESSO BRASILEIRO DA ABEQUA, 10., 2005. Guarapari-ES. Anais.

TOLDO Jr., E. E.; ALMEIDA, L. E. S.; BARROS, C. A. M. L. R. Retreat of the Rio Grande do Sul Coastal Zone, Brazil. In: MARTINS L. R.; SANTANA C. I. (Eds.). Non Living Resources of the Southern Brazilian Coastal Zone and Continental Margin. Porto Alegre: Editora UFRGS, 1999.

VILLWOCK, J. A. Geology of the Coastal Province of Rio Grande do Sul. Pesquisas, v. 16, p. 5-49, 1984.

. A costa brasileira: geologia e evolução. Notas Técnicas, v. 7, p. 38-49, 1994

Recebido em julho de 2010.

Aceito em outubro de 2010. Publicado em dezembro de 2010. 